abnormal records (Millichap JG. Attention Deficit Hyperactivity and Learning Disorders. Questions \& Answers. Chicago, PNB Publ, 1998). Oettinger F also reported a $7 \%$ incidence of "very specific" EEG abnormalities, compatible with a susceptibility to generalized or partial epilepsies, findings that altered his traditional approach to treatment of $\mathrm{ADHD}$ with stimulants (In: Learning Disabilities and Related Disorders. Ed. Millichap JG, Chicago, Year Book Med Publ, 1977). The difference in incidence of "epileptiform" records in my study compared to that of Dr Hughes and associates may be more apparent than real, and merely a matter of interpretation. In this regard, I defer to the experience and opinion of Dr Hughes. In any event, these figures are indicative of a need to consider specific indications to obtain an EEG in patients presenting with symptoms of ADHD.

Indications for an EEG in ADHD may include the following:

1) a personal or close family history of seizures; 2) inattentive episodes characterized by excessive "daydreaming" and/or periodic confused states; 3) comormid episodic, unprovoked temper or rage attacks; 4) frequently recurrent headaches; 5) a history of head trauma, encephalitis or meningitis preceding the onset of ADHD; 6) abnormalities on neurologic examination indicative of brain damage or defect. An ambulatory or video-EEG may be necessary to evaluate the significance of some reported paroxysmal symptoms, a question that I refer to my colleagues, Drs Nordli and Kelly, at our Epilepsy Center.

When to treat with AFDs. Treatment with antiepileptic drugs (AEDs) in ADHD patients with an epileptiform EEG, but without definite seizures, is a difficult and controversial decision. Indications to treat may include one or more of the following: 1) recurrent, clinically recognized seizures; 2) frequent episodic symptoms, suggestive of seizures, not amenable to behavioral intervention; 3) treatment with stimulant and antidepressant drugs in doses known to lower the threshold to seizures. The potential toxicity, adverse effects on learning, and need for frequent monitoring of AEDs must be weighed against the possible benefits in children with ADHD.

\title{
TRANSITORY COGNITIVE DEFICIT WITH EPILEPSY PAROXYSM
}

The EEGs and cognitive responses during a go-no go Continuous Performance Test (CPT) were studied in two groups of 58 epileptic and 20 healthy control chiuldren, ages 8 to 12 years, at the Hospital Civil de Guadalajara, Mexico. Paroxysmal discharges occurred in $88 \%$ of the epileptic compared to $5 \%$ of the control group. Transitory cognitive impairments (TCI) with higher numbers of behavioral errors and longer reaction times were detected in $36 \%$ of the epilepsy patients, in the absence of clinical seizures. TCI was correlated with the frequency and duration of paroxysmal discharges, occurring with discharges at more than 5 per second and lasting longer than $500 \mathrm{~ms}$. (Gonzalez-Garrido AA, Oropeza de Alba JL, Gomez-Velazquez FR et al. Transitory cognitive impairment in epileptic children during a CPT task. Clin Electroencephalogr October 2000;31:175180). (Reprints: Dr AA Gonzalez-Garrido, Hospital Civil de Guadalajara, Hospital 270, Col El Retiro, Torre de Especialidades, 8vo Piso, Guadalajara, Jalisco, CP 44280, Mexico).

COMMENT. The epileptic paroxysm, even without clinical seizure, can be associated with transitory cognitive impairment. Treatment of epilepsy may need to focus on control of EEG epileptiform discharges in addition to control of seizures. 
Hirsch E and colleagues (Strasbourg, France) report a significant relationship between a slow EEG focus and neuropsychological impairment, in a prospective study of 18 children with benign epilepsy with centro-temporal spikes (BECTS). Low performance on Koh's cube and WISC coding test correlate with the amount of spike and wave on sleep EEGs. (Abstracts frtom the Annual Meeting of the AES, Los Angeles, CA, December 1-6, 2000. Epilepsia Oct 2000;41:Suppl 7; 88).

Caplan R et al (UCLA, CA) studied thought disorder in 92 children with complex partial seizures (CPS), 51 with petit mal (PGE), and in 117 normal children, ages 5 to 16 years. The CPS group had more severe thought disorder and cognitive impairments than the PGE group. EEG evidence of fronto-temporal dysfunction in children with CPS was associated with thought disorder as well as global cognitive dysfunction. In the PGE group, thought disorder was related to poor seizure control and cognitive dysfunction. (Abstracts from the Annual Meeting of the AES, Los Angeles, CA, December 1-6, 2000. Epilepsia Oct 2000;41:Suppl 7;88).

\section{SELF-ESTEEM IN LEARNING-DISABLED CHILDREN WITH ADHD}

The level of self-esteem was measured, using the Piers-Harris Self-Concept Scale, in 143 special education students at high risk for ADHD in the school year 1995, at a school district in Northern Florida. Overall, self-esteem scores were in the normal range. Children with ADHD and internalizing symptoms (anxiety or depressive disorders, diagnosed in $29 \%$, according to child self-report questionnaires) had significantly lower self-esteem scores, compared to children with $\mathrm{ADHD}$ alone or $\mathrm{ADHD}$ with comorbid disruptive behaviors. Those with higher levels of functional impairment were also at greater risk for low self-esteem. Children from minority backgrounds, primarily African-American, had higher self-esteem scores than white children. Medication use was not an independent predictor of low self-esteem. (Bussing R, Zima BT, Perwien AR. Self-esteem in special education children with ADHD: relationship to disorder characteristics and medication use. LAm Acad Child Adolesc Psychiatry October 2000;39:1260-1269). (Respond: Dr Regina Bussing, Box 100177 UFHC, Gainesville, FL. 32610).

COMMENT. Comorbid internalizing (anxiety or depression) symptoms and severe learning or emotional dysfunction can predict low self-esteem in ADHD children. Minority background and use of stimulant medication do not increase risk of low self-esteem. In fact, African-American children with ADHD have a relatively higher level of self-esteem than their white counterparts.

\section{REGIONAL BRAIN VOLUME AND COGNITIVE OUTCOME IN PRETERM INFANTS}

Regional cortical volumes, measured by structural magnetic resonance imaging scans, were compared in 25 eight-year-old preterm children and 39 term control children, in a study performed at Yale and Brown University Medical Schools, and reported from the Yale Child Study Center, New Haven, CT. Regional cortical volumes were significantly smaller in the preterm children, especially in sensorimotor areas, but also in premotor, midtemporal, parieto-occipital, and subgenual cortices. Preterm children had significantly larger occipital and temporal, ventricular horns, and smaller volumes of cerebellum, basal ganglia, amygdala, hippocampus, and corpus callosum. The lower volumes of sensorimotor and midtemporal cortices in preterms were correlated with impaired full-scale, verbal, and performance IQ scores. (Peterson BS, Vohr B, Staib LH et al. Regional 